\title{
Health-Related Quality of Life of Cancer Patients Receiving Chemotherapy
}

\author{
${ }^{1}$ Manal M. Anwar, ${ }^{1}$ Heba R. Elareed and ${ }^{2}$ Ahmed Hassan \\ ${ }^{1}$ Public Health and Community Medicine, ${ }^{2}$ Clinical Oncology Department Faculty of \\ Medicine, Beni-Suef University, Egypt
}

\begin{abstract}
Background: Cancer is one of the chronic diseases highly influence people's health and Quality of life (QOL). QOL has become a significant outcome measure in the treatment of cancer patients. Objective: To assess cancer patients' QOL and its related consequences in relation to different chemotherapy treatment schedules. Method: This was a cross-sectional study among 200 cancer patients in Oncology Clinic, Beni-Suef University hospital. The European Organization for Research and Treatment of Cancer Quality of life Questionnaire was used to measure quality of life for the participating patients. Results: The study showed that $40.5 \%$ of patients with unfavorable physical functioning and $36.5 \%$ with emotional dysfunction, while the favorable category represented $50.5 \%, 43 \%$ and $41 \%$ for role, social and cognitive functioning respectively. Symptoms scales showed that $62.5 \%, 60 \%, 56 \%, 55.5 \%$ and $50.5 \%$ of studied cancer patients had fairly favorable fatigue, pain, appetite loss, financial difficulties and insomnia respectively, while $60 \%$, $59 \%$ and $43.5 \%$ of them had favorable symptoms of constipation, diarrhea and nauseavomiting respectively. There was a statistically significant association between quality of life and income. The fairly favorable and enough income was $54.5 \%$ vs. $48.7 \%$ for not enough income $(\mathrm{P}=0.0001)$. As for onset of cancer; the fairly favorable and the less than one-year onset was $58.5 \%$ vs $34.3 \%$ for more than one-year onset $(\mathrm{P}=0.005)$. As for stage of cancer; the favorable and cancer stage I showed $46.7 \%$ vs $13.7 \%$ for stage $4(\mathrm{P}=0.001)$. A strong association was found between QOL and number of CT cycles. Patients treated with $\leq 2$ CT cycles and fairly favorable QOL represented $56.7 \%(\mathrm{P}<0.001), 66.1 \%$ for those received 3-5 cycles and fairly favorable QOL $(\mathrm{P}<0.001)$ and $42.9 \%$ for those treated with $\geq 6$ cycles and unfavorable QOL $(\mathrm{P}<0.001)$. Conclusion: A Chemotherapy cycle may improve QOL in patients with solid tumors. Half of cancer patients undergoing chemotherapy treatment had fairly favorable QOL.
\end{abstract}

Keywords: Cancer; Chemotherapy (CT); Quality of life (QOL).

Correspondence: Heba R. Elareed, Email: dr_heba_alareed@yahoo.com

\section{Introduction}

Performance of cancer patients might be impaired because of their sufferings related to the symptom burden and advancement of the disease stage. Alleviating their symptoms (e.g. fatigue, dyspnea, cough, loss of appetite and pain) and effective management would relief their suffering and help improving their quality of life (QOL). The prevalence of many symptoms reflects an advanced stage and has been associated with emotional ill-being, poor physical and societal involvement with a decrease in the global QOL. ${ }^{1,2}$

One of the recent concepts accepted as a criterion to evaluate treatment results in patients with chronic physical (cancer) and mental diseases, is quality of life 
(QOL). Health-related quality of life (HRQOL) - an accepted concept to evaluate cancer treatment results- is a multi-dimensional concept that includes domains related to physical, mental, emotional, and social functioning. ${ }^{3}$ Quality of life is defined by the World Health Organization (WHO) as an individual's perception of life, culture, values, goals, expectations, standards, and concerns. ${ }^{4}$ Cancer poses a physical and mental stress for example: pain, depression, nutritional disturbances and disease progression consequences may be reflected on the whole family social well being as well as posing an economic burden. ${ }^{5,6}$

Recently, progress in cancer treatment improved survival; thus, an important surrogate is to improve the treatment related quality of life of cancer patients; especially for those with long term survivorship. ${ }^{7}$

Cancer survivors might suffer from longterm social/emotional problems. Hence, their support (spiritual/ philosophical) and maintaining their body image is of a major concern. ${ }^{8-10}$

Specialized cancer specific health care team aims at maximizing the occupational abilities and improving physical, mental and social aspects performance of cancer patients. ${ }^{7,11}$

The aim of this study is to assess cancer patients' QOL and its related consequences in relation to different chemotherapy treatment cycles.

\section{Method}

Study site: This study was carried out in a tertiary care hospital (Beni-Suef University hospital) - Beni Suef Governorate, Egypt. Study design: This is a descriptive cross-sectional study.

Sample size: A convenient sample of 200 patients who presented to the oncology clinic from February to August 2018. The sample size was estimated using
Epi-Info version 7 Stat Calc, [Center for Disease Control (CDC), WHO], depending on the following criteria; confidence level of $95 \%$, a margin of error of $5 \%$.

Inclusion criteria: Age $\geq 18$ years, Confirmed diagnosis with cancer, Under chemotherapy treatment, No history of other chronic disease such as diabetes or heart disease.

\section{Data collection tool}

The European Organization for Research and Treatment of Cancer QOL Questionnaire (EORTC QLQ-C30) was used to measure QOL for the participating patients. $^{12}$ The questionnaire is in English language; it was translated into Arabic and then back translated into English, to ensure correct translation of the questions. The Arabic version was revised by 7 experts and tested in a pilot study on 20 patients. The reliability of the questionnaire was tested by Cronbach alpha and found to be 0.81 .

The questionnaire included 44 questions in two parts: The first part: (14 Questions) including sociodemographic variables and patients' characteristics such as age, gender, educational level, marital status, employment, residence, and monthly income. In addition to tumor characteristics such as: stage, timing and number of chemotherapy cycles. The second part (30 Questions): European Organization for Research and Treatment of Cancer Quality of life questionnaire (EORTC-QOL-C30). Each question had an equal value and the QOL was quantified as the sum of the scores. The QOL-C30 is composed of both multiitem scales and single-item measures. All of the scales and single-item measures range from score 0 to 100 . A high scale score represents a higher response level. A high score for a functional scale represents a high / healthy level of functioning; a high score for the global 
health status / QOL represents a high QOL, but a high score for a symptom Table (1): The scoring system for the Quality of life questionnaire was according to the following

\begin{tabular}{|l|l|l|l|}
\hline \multirow{2}{*}{ Scale } & \multicolumn{3}{c|}{ Degree of Quality of Life } \\
\cline { 2 - 4 } & Unfavorable & Fairly favorable & Favorable \\
\hline Functional & $0-33.3$ & $33.3-66.6$ & $\geq 66.6$ \\
\hline Symptom & $\geq 66.6$ & $33.3-66.6$ & $0-33.3$ \\
\hline
\end{tabular}

The subjects were asked to rate how true each statement is 7 days ago with a response scale ranging from 1 to 4 "Not at all", "A little", "Quite a bit" and "Very much.".

Regarding the overall QOL, the respondents were asked to circle the number that represents how they feel about their health and quality of life at the present time ranging from 1 to 7 . The number (1) represents the worst possible life and the number (7) represents the best possible life. The scores were classified into three categories: unfavorable, fairly favorable, and favorable. The higher the scores the better QOL is.

The patients were given approximately twenty minutes to complete the questionnaire aided by medical students to fill up the questionnaire by reading loud the questions for them and their answers were recorded.

\section{Statistical analysis}

Data were collected, coded and entered to computer before being analyzed using the software, Statistical Package for Social Science, (SPSS) version 20 (IBM, USA). For analysis purpose, frequency distribution as percentage and descriptive statistics in the form of mean and standard deviation were calculated. Comparisons of qualitative data were performed using Chi-squared test. The level of statistical significance was set to be $\leq 0.05$

\section{Ethical consideration}

After institutional approvals, The Faculty of Medicine, Beni-Suef University scale / item represents a high level of symptoms / problems.

Research Ethics Committee has approved the study protocol. The study objectives and procedures were explained in details for each participant and it was clearly explained to participants that the results would not be declared. Participation in the study was intended to be voluntary and a written informed consent was obtained from each participant prior to inclusion in the study.

\section{Results}

Regarding functional scales, $40.5 \%$ of patients showed unfavorable physical functioning and $36.5 \%$ were emotional functioning, while the favorable category represented $50.5 \%, 43 \%$ and $41 \%$ for role, social and cognitive functioning respectively.

Symptoms scales showed that $62.5 \%$, $60 \%, 56 \%, 55.5 \%$ and $50.5 \%$ of studied cancer patients had fairly favorable fatigue, pain, appetite loss, financial difficulties and insomnia respectively, while $60 \%, 59 \% 43.5 \%$ of them had favorable symptoms of constipation, diarrhea and nausea-vomiting respectively (Table 1)

Table 2 showed that the study patients' mean age was $51.19 \pm 14.4$ years (range 20-87 years). Female participants were $56.5 \%$ and $43.5 \%$ were males; $68.5 \%$, of study participants were illiterate, $62.5 \%$ were jobless, $84 \%$ were married and $91 \%$ resided in rural areas. Among the study group; $65 \%$ were diagnosed with cancer for more than one year, $37 \%$ had stage III disease and $53.5 \%$ were diagnosed to 
have distant metastasis. Breast cancer patients constituted $22 \%$, followed by lung cancer $12.5 \%$, gastrointestinal malignancies $11 \%$, lymphomas $12.5 \%$,

Table (1): Quality of life scoring among cancer patient.

\begin{tabular}{|c|c|c|c|c|}
\hline \multicolumn{2}{|c|}{ Items } & $\begin{array}{c}\text { Unfavorable } \\
\text { N }(\%)\end{array}$ & $\begin{array}{c}\text { Fairly favorable } \\
\text { N }(\%)\end{array}$ & $\begin{array}{c}\text { Favorable } \\
\mathbf{N}(\%)\end{array}$ \\
\hline \multicolumn{2}{|c|}{ Global Health Status/ QOL } & $64(32)$ & $100(50)$ & $36(18)$ \\
\hline \multirow{5}{*}{ 预 } & Physical functioning & $81(40.5)$ & $71(35.5)$ & $48(24)$ \\
\hline & Role functioning & $48(24)$ & $51(25.5)$ & $101(50.5)$ \\
\hline & Emotional functioning & $73(36.5)$ & $68(34)$ & $59(29.5)$ \\
\hline & Cognitive functioning & $44(22)$ & $74(37)$ & $82(41)$ \\
\hline & Social functioning & $41(20.5)$ & $73(36.5)$ & $86(43)$ \\
\hline \multirow{9}{*}{ 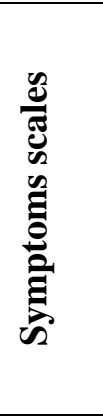 } & Fatigue & $58(29)$ & $125(62.5)$ & $17(8.5)$ \\
\hline & Nausea and vomiting & $28(14)$ & $85(42.5)$ & $87(43.5)$ \\
\hline & Pain & $51(25.5)$ & $120(60)$ & $29(14.5)$ \\
\hline & Dyspnea & $42(21)$ & $79(39.5)$ & $79(39.5)$ \\
\hline & Insomnia & $45(22.5)$ & $101(50.5)$ & $54(27)$ \\
\hline & Appetite loss & $31(15.5)$ & $112(56)$ & $57(28.5)$ \\
\hline & Constipation & $11(5.5)$ & $69(34.5)$ & $120(60)$ \\
\hline & Diarrhea & $12(6)$ & $70(35)$ & $118(59)$ \\
\hline & Financial difficulties & $30(15)$ & $111(55.5)$ & $59(29.5)$ \\
\hline
\end{tabular}

genitourinary $15 \%$, liver cancer $17 \%$, and others $10 \%$.

As regard the global health status in relation to disease and sociodemographic factors; the study illustrated statistically significant difference between global health status / QOL and income $(\mathrm{P}=0.0001)$, onset of cancer $(\mathrm{P}=0.005)$ and cancer stage $(\mathrm{P}=0.001)$.

Relation between global health status / QOL and number of chemotherapy cycles is shown in Table 3 . Half of patients showed a fairly favorable QOL status. A strong association was found between QOL and number of CT cycles with a significant difference between the levels of QOL for patients treated with $\leq$ 2 CT cycles $(\mathrm{P}<0.001)$, with $3-5$ cycles $(\mathrm{P}<0.001)$ and those treated with $\geq 6$ cycles $(\mathrm{P}<0.001)$.

\section{Discussion}

Cancer treatment related mental and health effects were found to affect patients' health related QOL; particularly in advanced stages. Several studies support these findings especially with adoption of chemotherapy.
Functional scales; the present study showed that favorable role, social, cognitive functioning were reported in $45-50 \%$. Findings that was similar to the reported physical well being of patients undergoing chemotherapy 13,14 and contrary to a report showing significant affection of physical domain on QOL in breast cancer patients'. ${ }^{15}$ Psychological domain had no correlation with mode of treatment of cancer in agreement with a similar study finding. ${ }^{16}$

Symptoms scale; study participants had favorable gastrointestinal side effects followed by nausea \& vomiting. Fairly favorable scale was highest for pain, loss of appetite and financial difficulties (Table1), findings that were comparable to international reports showing that poor health-related quality of life (HRQOL) among cancer patients is associated with multiple factors, including sleep disturbances, fatigue, pain, anxiety, and depression. $^{13,17}$ Discrepancies between our findings and others might be attributed to the adoption of different study tools, different spectrum of cancer patients' population demographics, e.g.: history of disease onset, different 
chemotherapy regimens and performance of the patients.

The present study showed no association between QOL and demographic data.

Table (2): Global health status in relation to disease and socio-demographic factors

\begin{tabular}{|c|c|c|c|c|c|}
\hline \multirow{2}{*}{$\begin{array}{c}\text { Characters of the } \\
\text { patients }\end{array}$} & \multirow{2}{*}{$\begin{array}{c}N(\%) \\
\text { Total }=200\end{array}$} & \multicolumn{4}{|c|}{ Global Health Status/ QOL } \\
\hline & & $\begin{array}{c}\text { Un favorable } \\
\text { N }(\%)\end{array}$ & $\begin{array}{c}\text { Fairly favorable } \\
\text { N }(\%)\end{array}$ & $\begin{array}{c}\text { Favorable } \\
\mathbf{N}(\%)\end{array}$ & P-Value \\
\hline $\begin{array}{l}\text { Age } \\
\text { Mean } \pm S D ;(\text { range })\end{array}$ & \multicolumn{5}{|c|}{$51.19 \pm 14.4 ;(20-87)$} \\
\hline $\begin{array}{l}\text { Sex } \\
\text { - Male } \\
\text { - Female }\end{array}$ & $\begin{array}{r}87(43.5) \\
113(56.5)\end{array}$ & $\begin{array}{l}25(28.7) \\
39(34.5)\end{array}$ & $\begin{array}{l}50(57.5) \\
50(44.2)\end{array}$ & $\begin{array}{l}12(13.8) \\
24(21.3)\end{array}$ & 0.154 \\
\hline $\begin{array}{l}\text { Education } \\
\text { - Illiterate } \\
\text { - Primary } \\
\text { - Secondary } \\
\text { - University } \\
\end{array}$ & $\begin{array}{r}137(68.5) \\
27(13.5) \\
23(11.5) \\
13(6.5) \\
\end{array}$ & $\begin{array}{r}43(31.4) \\
12(44.5) \\
5(21.7) \\
4(30.8) \\
\end{array}$ & $\begin{array}{r}66(48.2) \\
11(40.7) \\
17(73.9) \\
6(46.1) \\
\end{array}$ & $\begin{array}{r}28(20.4) \\
4(14.8) \\
1(4.4) \\
3(23.1)\end{array}$ & 0.205 \\
\hline $\begin{array}{l}\text { Occupation } \\
\text { - Not working } \\
\text { - Farmer } \\
\text { - Worker } \\
\text { - Employee } \\
\end{array}$ & $\begin{array}{r}125(62.5) \\
38(19) \\
19(9.5) \\
18(9)\end{array}$ & $\begin{array}{r}40(32) \\
14(36.8) \\
6(31.6) \\
4(22.2)\end{array}$ & $\begin{array}{r}65(52) \\
18(47.4) \\
8(42.1) \\
9(50) \\
\end{array}$ & $\begin{array}{l}20(16) \\
6(15.8) \\
5(26.3) \\
5(27.8)\end{array}$ & 0.774 \\
\hline $\begin{array}{l}\text { Income } \\
\text { - Enough } \\
\text { - Not enough } \\
\end{array}$ & $\begin{array}{r}44(22) \\
156(78) \\
\end{array}$ & $\begin{array}{r}14(31.8) \\
50(32) \\
\end{array}$ & $\begin{array}{l}24(54.5) \\
76(48.7)\end{array}$ & $\begin{array}{r}6(13.7) \\
30(19.3)\end{array}$ & 0.0001 \\
\hline $\begin{array}{l}\text { Marriage } \\
\text { - Single } \\
\text { - Married } \\
\text { - Widow } \\
\text { - Divorced }\end{array}$ & $\begin{array}{r}9(4.5) \\
168(84) \\
22(11) \\
1(0.5)\end{array}$ & $\begin{array}{r}4(44.5) \\
53(31.5) \\
7(31.8) \\
0(0)\end{array}$ & $\begin{array}{r}2(22.2) \\
88(52.4) \\
10(45.5) \\
0(0)\end{array}$ & $\begin{array}{r}3(33.3) \\
27(16.1) \\
5(22.7) \\
1(100)\end{array}$ & 0.206 \\
\hline $\begin{array}{l}\text { Residence } \\
\text { - Urban } \\
\text { - Rural } \\
\end{array}$ & $\begin{array}{r}18(9) \\
182(91) \\
\end{array}$ & $\begin{array}{r}5(27.8) \\
59(32.4) \\
\end{array}$ & $\begin{array}{l}11(61.1) \\
89(48.9)\end{array}$ & $\begin{array}{r}2(11.1) \\
34(18.7) \\
\end{array}$ & 0.571 \\
\hline $\begin{array}{l}\text { Onset of cancer } \\
\text { - One year ago } \\
\text { - More than one year }\end{array}$ & $\begin{array}{r}130(65) \\
70(35)\end{array}$ & $\begin{array}{l}34(26.2) \\
30(42.9)\end{array}$ & $\begin{array}{l}76(58.5) \\
24(34.3)\end{array}$ & $\begin{array}{l}20(15.3) \\
16(22.9)\end{array}$ & 0.005 \\
\hline $\begin{array}{l}\text { Cancer stage (TNM) } \\
-1 \\
-12 \\
-3 \\
-4\end{array}$ & $\begin{array}{r}15(7.5) \\
60(30) \\
74(37) \\
51(25.5)\end{array}$ & $\begin{array}{r}5(33.3) \\
28(46.7) \\
19(25.7) \\
12(23.5)\end{array}$ & $\begin{array}{r}3(20) \\
25(41.7) \\
40(54) \\
32(62.8)\end{array}$ & $\begin{array}{r}7(46.7) \\
7(11.6) \\
15(20.3) \\
7(13.7)\end{array}$ & 0.001 \\
\hline $\begin{array}{l}\text { Metastasis } \\
\text { - Yes } \\
\text { - No } \\
\end{array}$ & $\begin{array}{r}107(53.5) \\
93(46.5) \\
\end{array}$ & $\begin{array}{r}38(35.5) \\
26(28) \\
\end{array}$ & $\begin{array}{r}47(43.9) \\
53(57) \\
\end{array}$ & $\begin{array}{r}22(20.6) \\
14(15)\end{array}$ & 0.180 \\
\hline $\begin{array}{l}\text { Type of cancer } \\
\text { - Breast cancer } \\
\text { - Lung cancer } \\
\text { - GIT } \\
\text { - Lymphoma } \\
\text { - GU } \\
\text { - Liver } \\
\text { - Others* }\end{array}$ & $\begin{array}{r}44(22) \\
25(12.5) \\
22(11) \\
25(12.5) \\
30(15) \\
34(17) \\
20(10)\end{array}$ & $\begin{array}{r}13(29.5) \\
8(32) \\
7(31.8) \\
9(36) \\
8(26.7) \\
10(29.4) \\
6(30)\end{array}$ & $\begin{array}{r}20(45.5) \\
10(40) \\
9(40.9) \\
10(40) \\
15(50) \\
16(47.1) \\
7(35)\end{array}$ & $\begin{array}{r}11(25) \\
7(28) \\
6(27.3) \\
6(24) \\
7(23.3) \\
8(23.5) \\
7(35)\end{array}$ & 0.682 \\
\hline
\end{tabular}

*Others: Head and neck, Soft tissue sarcoma
Similar results were reported internationally ${ }^{18}$ and only one study 
Table 3: Global Health Status/QOL in cancer patients according to number of chemotherapy cycles

\begin{tabular}{|c|c|c|c|c|c|}
\hline \multirow[b]{2}{*}{$\begin{array}{c}\text { Chemotherapy } \\
\text { cycles }\end{array}$} & \multicolumn{4}{|c|}{ Global Health Status/QOL } & \multirow[b]{2}{*}{ P- Value } \\
\hline & $\begin{array}{c}\text { Unfavorable } \\
\mathbf{N}(\%)\end{array}$ & $\begin{array}{c}\text { Fairly } \\
\text { favorable } \\
\mathbf{N}(\%) \\
\end{array}$ & $\begin{array}{c}\text { Favorable } \\
\mathbf{N}(\%)\end{array}$ & $\begin{array}{l}\text { Total } \\
\text { N }(\%)\end{array}$ & \\
\hline Less than 2 & $17(28.3)$ & $34(56.7)$ & $9(15)$ & $60(30)$ & 0.001 \\
\hline $3-5$ & $11(19.6)$ & $37(66.1)$ & 8 (14.3) & $56(28)$ & 0.001 \\
\hline More than 6 & $36(42.9)$ & $29(34.5)$ & $19(22.6)$ & $84(42)$ & 0.001 \\
\hline Total & $64(32)$ & $100(50)$ & $36(18)$ & $200(100)$ & 0.001 \\
\hline
\end{tabular}

A strong association between disease onset and QOL is shown in table 2. Similar findings were reported confirming an impaired QOL with the longer elapsed time since initial diagnosis ${ }^{20}$ and opposite to one study report showing no association between disease onset and QOL. ${ }^{21}$ The difference might be due to the fact that more than half of the study population was diagnosed with metastatic disease.

In this study, $66.1 \%$ and $14.3 \%$ of patients who completed 3-5 cycles of chemotherapy had a fairly favorable and favorable level of QOL (Table 3), similar to other international studies reporting that the majority of cancer patients had moderate QOL after 2-4 chemotherapy cycles ${ }^{18}$ and a good / appropriate QOL post chemotherapy, ${ }^{(22)}$ whilst contrary to others who reported below average / poor QOL among cancer patients undergoing chemotherapy. ${ }^{8,} 13$, ${ }^{23,} 24$ Difference between our findings and others might be explained by the diversity of the inclusion criteria and the prevalence of advanced stage diseases of other studies.

Recently; QOL has been accepted as an endpoint for treatment comparisons and an early indicator of disease progression for many cancer types, particularly in advanced stages. Improving QOL is as important as the survival benefit offered by recent medications. Reducing mortality and ensuring optimal health

\section{Conclusion}

Cancer chemotherapy treatment related issues affect health related QOL. In the present fairly favorable quality of life was experienced by half of the study patients with a statistically significant difference between global QOL and number of Chemotherapy cycles. Patients' income, cancer stage, onset of cancer and socio-demographic characteristics had no impact on QOL. Un-favorable physical and emotional functional scales in addition to fairly favorable pain, fatigue, loss of appetite and financial difficulties are unwanted effects of cancer related treatment affecting HRQOL that need to be dealt with in order to improve cancer patients' well being. Socioeconomic support is hence a necessity to improve health related quality of life for such patients.

\section{Conflict of interest}

The authors have no conflict of interest to declare.

\section{Funding}

There was no source of funding.

\section{Authors' contributions}

MA, HE and AH conceived and designed study, finalized the methodology and tools used. AH helping in data collection, MA and HE analyzed and drafted the manuscript. All the authors made significant contributions in manuscript 
writing and finalizing the manuscript. The final manuscript has been read and approved by all the authors.

\section{Acknowledgement}

The authors would like to thank medical students; Taha Ragab Rashed and Reda Sayed Abdel Shafy - faculty of medicine - Beni-Suef University. They helped in data collection and filling the questionnaire for illiterate patients. Moreover, we would like to thank all of the patients who participated in this study.

\section{References}

1- Paleri A, Kumar S, Thankam K. Manual for Palliative Care. 2005.

2- Heidrich SM, Egan JJ, Hengudomsub P, Randolph SM. Symptoms, symptom beliefs, and quality of life of older breast cancer survivors: A comparative study. Oncol Nurs Forum. 2006; 33:315-22.

3- Kuehner C, Buerger C. Determinants of subjective quality of life in depressed patients: the role of self-esteem, response styles, and social support. J Affect Disord 2005; 86(2-3): 205-13.

4- WHO (World Health Organization): WHOQOL: Measuring Quality of Life. Available at https://www.who.int/healthinfo/survey/ whoqol-quality of life/en/ Accessed March 28, 2018.

5- Shakeri J, Abdoli N, Paianda M, Chareh-Ga G. The frequency distribution of depression among patients with breast cancer in Kermaneshahu.m.s chemotherapy centers in 2007. Journal of Medical Council of Islamic Republic of Irans. 2009;27(3):324328.

6- Safaee A, Moghimi-Dehkordi B, Zeighami B, Tabatabaee HR, Pourhoseingholi MA. Predictors of quality of life in breast cancer patients under chemotherapy. Indian Journal of Cancer. 2008;45(3):107-111.

7- Lianqi Liu, Lavinia Fiorentino, Michelle Rissling, Loki Natarajan, Barbara A. Parker, Joel E. Dimsdale, Paul J. Mills, Georgia Robins Sadler, Sonia Ancoli-Israel. Decreased Health-Related Quality of Life in
Women with Breast Cancer is Associated with Poor Sleep. Behav Sleep Med. 2013 July; 11 (3): 189-206.

8- Casso D, Buist DS, Taplin S. Quality of life of 5-10 year breast cancer survivors diagnosed between age 40 and 49. Health Qual Life Outcomes 2004; 2:25.

9- Ganz PA, Desmond KA, Leedham B, Rowland JH, Meyerowitz BE, Belin TR. Quality of life in long-term disease-free survivors of breast cancer: a follow-up study. J Natl Cancer Inst 2002; 94:39-49.

10- Kornblith AB, Herndon JE, Silverman LR, Demakos EP, Reissig, Kornblith AB et al. Long-term adjustment of survivors of early stage breast carcinoma 20 years after adjuvant chemotherapy. Cancer 2003; 98:679-689.

11- Mardani Hamule M, Shahraky Vahed A. The Assessment of Relationship between Mental Health and Quality of Life in Cancer Patients. Scientific Journal of Hamadan University of Medical Sciences. 2009;16(2):33-38.

12- EORTC QLQ-C30 Reference Values. Fayers PM, Weeden S, Curran D, on behalf of the EORTC Quality of Life Study Group. Brussels: EORTC, 1998. ISBN: 2-93006411-0. (The reference values are also available on CD-ROM)

13- Shalini S, Jeseena K, Vivek K, Shashi Bhushan S, Mithilesh K. Study on Quality Of Life of Cancer Patients In Relation To Treatment Modality in a Tertiary Health Institute of Jharkhand IOSR Journal of Dental and Medical Sciences (IOSR-JDMS) 2016; 5(15):16-20

14- Kanayamkandi J, Sunderam S. Quality of life among breast cancer patients: a cross sectional study Int J Community Med Public Health. 2017;4(3):686-689

15- Yedukondala Rao A, Sudhakar G. A Prospective Observational Analysis Reasons for Poor Quality of Life in Cancer Patient Population of South Indian Territory Hospital. Int $\mathbf{J}$ Scientific Research. 2015;4(9):654-6.

16- Chaturvedi S. What"s important for quality of life to Indians in relation to cancer? Indian J Palliat Care, 2003; 9:62-70. 17- Liu L, Fiorentino L, Rissling M, Natarajan L, Parker B, Dimsdale J et al. 
Decreased Health-Related Quality of Life in Women with Breast Cancer is Associated with Poor Sleep. Behav Sleep Med. 2013; 11 (3): 189-206.

18- Dehkordi AH, Heydarnejad MS, Fatehi D. Quality of life in cancer patients undergoing chemotherapy.OMJ.2009;24:204-207

19- Aghabarari M, Ahmadi F, Mohamadi A, Hajizadeh A, Farahani A. Physiology, psychology and social dimentions quality of life in woman with breast cancer treatment with chemotherapy. Iranian Jour-nal of Nursing Research 2006; 1(3): 55-6.

20- Holzner B, Kemmler G, Kopp M, Moschen R, Schweigkofler H, Dünser M et al. Quality of life in breast cancer patientsnot enough attention for long-term survivors. Psychosomatics 2001;117-123.

21- Heydarnejad MS, Dehkordi AH, Dehkordi SK. Factors affecting quality of life in cancer patients undergoing chemotherapy African Health Sciences 2011; 11(2): 266- 270

22- Farahnaz A, Shima SA, Azad R, Iraj AK. Quality of Life in Cancer Patients and its Related Factors Journal of Caring Sciences, 2012;1(2), 109-114

23- Kannan G, Rani V, Ananthanarayanan RM, Palani T, Nigam N, Janardhan $\mathrm{V}$ et al. Quality of life of cancer patients. Journal of Cancer Research and Therapeutic 2011; 7: 275-9

24- Holly.G. Pigerson, Bao Y, Shah MA. Chemotherapy use, performance status, and quality of life at the end of life. JAMA Oncol.2015;(6):778-784

25- Love C, Sabiston CM. Exploring the links between physical activity and posttraumatic growth in young adult cancer survivors. Psychooncology 2011; 20(3): 27886. 